\title{
Nonviolent Adult Sons of Abused Women: Ending the Cycle of Violence
}

\author{
Kim M. Anderson ${ }^{1, *}$, Laura Danforth ${ }^{2}$, Jennifer First ${ }^{3}$ \\ ${ }^{1}$ School of Social Work, Health and Public Affairs I, University of Central Florida, Orlando, USA \\ ${ }^{2}$ School of Social Work, University of Arkansas at Little Rock, Ross Hall 401, Little Rock, USA \\ ${ }^{3}$ School of Social Work, University of Missouri, 705 Clark, Columbia, USA
}

\begin{abstract}
This grounded theory inquiry aimed to elicit nonviolent adult sons' $(N=13)$ perceptions of what helped them to recover from childhood exposure to domestic violence (CEDV). Analysis of participants' transcripts revealed five important themes related to this transformation process: 1) committing to a life of nonviolence, 2) understanding and accepting the realities of their childhood, 3) choosing to forgive parents, 4) navigating adult child-parental contact and 5) accessing informal and formal support networks. This study's findings may be translated by helping professionals into prevention efforts and intervention strategies for male child witnesses to stop the cycle of violence.
\end{abstract}

Keywords Adult Child Witnesses, Stopping Abuse Cycle, Childhood Exposure

\section{Introduction}

Although research indicates that witnessing inter-parental violence as a child is related to short- and long-term consequences, there remains a dearth of knowledge in regard to males who end the cycle of violence in their own lives (Kitzmann, Gaylord, Holt \& Kenny, 2003; Russell, Springer, \& Greenfield, 2010; Wolfe, Crooks, Lee, McIntyre-Smith, \& Jaffee, 2003). Studies on interpersonal functioning of adult children often draw from men who are abusive and women who are experiencing domestic violence, yet these samples may not represent the experiences of adult children in general (Holt \& Gillespie, 2008; Humphreys, 2001). Most children who witness inter-parental violence and experience abuse in their families of origin will not perpetrate intimate partner violence in the future (Suzuki, Geffner, \& Bucky, 2008). In addition, many males and females reject or resist the patriarchal attitudes and beliefs espoused in their families of origin. While child witnesses include boys and girls, a few studies report gender differences regarding the impact of witnessing IPV (Evans, Davies \& DiLillio, 2008; Fagan \& Wright, 2011; Herrera \& McCloskey, 2001). Thus, exploring separately each gender's developmental trajectory allows for gender-based relevant discovery and explication of short and long-term impacts. Few studies have examined the perspectives and experiences of nonviolent adult sons exposed to IPV in their childhood. This qualitative study conducted 13 semi-structured interviews with nonviolent adult males to explore a) how they came to understand the injurious actions perpetrated on their mothers and themselves, and b) what contributes to their resolve to be different from their oppressors and therefore, choose to end a cycle of harming self and others rather than perpetuating it.

\section{Life Trajectories of Adult Children of Abused Women}

The life trajectories of adults who witnessed inter-parental violence during childhood are receiving more attention and the results of these studies demonstrate the obstacles for adult children of abused women (ACAW) to achieving successful psychosocial outcomes. For instance, compared to non-exposed men and women, they experience greater depression, self-doubt, anxiety, and posttraumatic stress disorder (PTSD) (Chartier, Walker, \& Naimark, 2010; Henning et al., 1996; Russell, Springer \& Greenfield, 2010). In most cases the lasting, major damage caused by childhood exposure is emotional and psychological, and for males in particular, it has lasting impacts on their academic trajectory, including a decline in academic school performance and an increased risk of dropping out of high school (Boxer \& Sloan-Power, 2013; Dick, 2005; Thompson \& Trice-Black, 2012).

ACAW are also more likely to use non-constructive strategies to resolve conflict in relationships, such as avoidance or aggression. In the context of an adult intimate relationship, males are more likely to show violent and 
aggressive behavior, particularly if during childhood they witnessed the use of weapons (Clements, Oxtoby \& Ogle, 2008; Dick, 2005; Murrell, Merwin, Christoff, \& Henning, 2005). Females tend to be the recipient of abuse in intimate relationships (Ireland \& Smith, 2009; Maker, Kemmelmeier $\&$ Peterson, 1998). Males are also more likely than their female counterparts to be divorced or separated, and less likely to be married (Band-Winterstein, 2014; Dick, 2005; Krieder \& Ellis, 2011).

In addition to perhaps experiencing physical violence and injury because of physically intervening between parents, many children experience abuse directly (Edleson et al., 2007; Gelles \& Straus, 1979). Domestic violence research shows a $30-60 \%$ overlap, and in the case of severe intimate partner violence, sons are more at risk of child abuse than girls (Jouriles et al., 2008). Exposure to multiple concurrent factors (e.g., child abuse and domestic violence) is often more predictive of maladaptation than the presence of any one factor itself (Mohr \& Tulman 2000; Morgolin \& Gordis 2004). Dube and colleagues (Dube et al., 2001) found that individuals who witnessed domestic violence during childhood and experienced child abuse were two to five times more likely to attempt suicide in adulthood compared with those who had experienced one type of adversity.

Studies show that people who witnessed and/or experienced aggression in their families as children are significantly more likely to be violent toward their intimate partners as adults (Hines \& Saudino, 2002; Stith et al., 2000; Stith et al., 2004). Individuals who see violence in their family of origin being rewarded learn to resolve conflicts and frustrations with others through violence. In other words, children learn through witnessing male-perpetrated aggression against their female partners, how to get what they want through violence. This direct model of marital aggression, more than the modeling children are exposed to when they experience child abuse, increases their chances of engaging in spousal abuse as an adult as they reproduce such patterns in their own intimate relationships (Kwong, Bartholomew, Henderson, \& Trinke, 2003; Renner \& Slack, 2006). The risk of an individual engaging in IPV, however, increases exponentially if that person has experienced both child abuse and witnessed domestic violence (Corvo \& de Lara, 2010; Ponce, Williams, \& Allen, 2004).

Intergenerational transmission of violence is an important area of study because of its legacy of destruction and devastation. However, the link between witnessing violence between parents, experiencing early childhood violence, and later adult partner aggression is complex. In addition to inquiry of negative impacts, more study is necessary that examines individuals' abilities to adapt, reorganize and regenerate in the midst of recovery. Thus, this qualitative study aimed to elicit nonviolent adult sons' perceptions of what helped them to prevent the cycle of violence in their own lives.

\section{Method}

\section{Research Design and Questions}

Since the intent of this study was to discover how one ends the cycle of violence, the grounded theory approach was particularly suited as its purpose is to identify complex and hidden psychosocial processes with the goal of developing theory (Glaser, 2001). The study's research question included: 1) what are the key resources and processes that contributed to stopping the cycle of violence from continuing for nonviolent adult sons of abused women?

\section{Criteria for Inclusion/Exclusion}

The sample was drawn from a large mixed methods study regarding recovery and growth in adult children $(N=86 ; n=68$, females; $n=18$, males) exposed to IPV during their childhood (for additional study information see Anderson \& Bang, 2012). Purposive sampling criteria for the larger study included adult children who met the following criteria: 1) 21 or older, 2) not living in their parents' home/childhood residence, and 3) had experienced (during childhood) their mothers being abused by intimate male partners in the household in which they were reared. All participants completed study documents and were asked if violence ever had been a part of their adult lives either as the perpetrator and/or the recipient. Their questionnaire responses were also triangulated with their interview responses. Of the 18 males who participated, five were excluded for the current study as they reported they had been abusive to an intimate partner.

\section{Participant Information}

Participants $(N=13)$ were males ranging in age from 23 to 60 years old $(M=34, S D=11)$. The majority were European American $(n=12)$ and one was African-American. Twelve self-identified as heterosexual. Educationally, three had some college (two of which were currently enrolled) and ten participants had completed a bachelor's and/or master's degrees. Eight were married and two were living with their intimate partners. Five had children of their own. Eleven participants reported full-time employment.

Approximately half of the participants $(n=7)$ were exposed to the abuser's violence for 10 or more years during childhood; one participant reported that it continued into young adulthood. At the time of the study, participants reported that the violence had ended due to parental divorce or death $(n=10)$ and/or their father's sobriety $(n=3)$. The types of violence exposure reported by all participants included physical and emotional abuse, and five reported that the abuser used weapons including guns, knives, and/or automobiles. Abusers included fathers $(n=9)$ and stepfathers $(n=4)$. 


\section{Procedure and Data Collection}

After approval by a university internal review board, participants were recruited through electronic advertisements to students, faculty, and staff at a Midwestern University in the United States. Potential participants were screened over the telephone by the first author to explain the interview process and to determine whether they met sampling criteria. Although domestic violence also includes abuse by women against men and same-sex partners, the focus was on the experience "in which most children exposed to domestic violence find themselves, in a home where a man is committing a pattern of violence against an adult woman, who is most often the child's mother" (Edleson et al., 2007, pg. 963). Patterns of violence included physical, verbal, sexual, and financial. Childhood exposure was defined as being within sight or sound of the violence or witnessing the aftermath of the violence (e.g., mother's injuries, property destruction, police intervention to remove the abuser, moving to a domestic violence shelter) (Edleson et al., 2007). Interviews were conducted in the first author's University office.

Although a semi-structured interview of open-ended questions was used, participants determined the emphasis they would place on different aspects of their stories and were given the freedom to describe the meaning they had given to their own experiences. Each interview began by the researchers asking participants to pick a pseudonym and to share their childhood experiences of exposure to their mothers' abuse. Participants were also asked to share how their life journeys were impacted by their childhood adversity and the formal and informal resources they accessed as a result. Each in-depth interview was approximately an hour and a half. Member (participant) checking included a 30-minute follow-up interview after participants had received a summary of the findings to gain their insights regarding the final analysis. At the conclusion of the second interview, participants were given a $\$ 20.00$ gift certificate to a national department store.

\section{Data Analysis}

After removing the participant identifiers, the audio recorded data was transcribed verbatim. The transcripts were entered into a qualitative analysis computer software, Dedoose (http://dedoose.com). Data were coded and organized by two researchers using a constant comparative method; a qualitative procedure that identifies and extracts significant statements or "meaningful units" from in-depth interview transcripts to be conceptualized and reconstructed in new ways (Oktay, 2012). A categorical-content approach was used as part of the grounded theory method as a means of attending to separate parts of the story within and between participants' narratives (Krippendorff, 1980). Initially, analysis involved searching for units of data (i.e., attitudes, beliefs, values, feelings, and goals) that could stand on their own and were associated with the overall purpose for the study. Using in-vivo or open coding, each line of transcript was assigned an action code (i.e., feeling angry, utilizing counseling services, getting out of father's control, setting boundaries, etc.). During this initial stage of coding, researchers utilized the words and ideas of the respondents to better understand their experiences and to designate data into early categories of "conveyed meanings" (Oktay, 2012, pg. 55). Next, axial coding was utilized in order to understand how these conveyed meanings were related to one another, to identify central themes, and to "move analysis from description to theory building" (Oktay, 2012. pg. 149). Finally, selective coding was used to group data into final categories that represented key psychosocial issues and patterns (e.g., personal and interpersonal strategies) related to stopping the cycle of violence from occurring in their adult lives. These patterns were analyzed by comparing them with one another, so that relevant themes (e.g., committing to nonviolence, choosing forgiveness, etc.) addressing the research question could emerge. Finally, a conceptual framework of ending the cycle of violence was generated around the core category of "empowered self" that described the central phenomenon relating to participants' experiences.

\section{Results}

Participants described an oppressive home environment characterized by fear and powerlessness. The core phenomenon that emerged included strategies used by them to transform childhood experiences of powerlessness into an empowered adult self that aligned with one's own voice and preferences rather than those of the past and their abusive father figures. Such strategies often occurred simultaneously at a personal level (changing patterns of thinking, behaving and feeling) and an interpersonal level (navigating their relationships more effectively) to improve their adult lives and contribute to their overall adaptation and growth. Analysis of participants' transcripts revealed five important themes related to the process of stopping the cycle of violence: 1) committing to a life of nonviolence, including choosing to act differently than their parents, 2) understanding and accepting childhood realities, including their fathers/stepfathers' abusive actions, 3) choosing to forgive parents, 4) navigating adult child-parental contact, particularly limiting exposure to violence and dysfunction, and 5) accessing informal and formal support networks, especially therapeutic.

\section{Commit to Nonviolence}

All participants staunchly refused to continue the cycle of violence in their lives, especially with intimate partners and children. Instead, they were committed to being kinder and more compassionate partners and fathers than what had been 
modeled for them. Specifically, all five participants who were fathers explained that having children strengthened their commitment to non-violence. The roots of their nonviolent pledge began in childhood as they promised themselves when they grew up to not have violence in their lives, to not expose their children to violence, and to be different from their parents. Participants' childhood experiences deterred them from being abusive because they knew first-hand how such behavior and its effects can reverberate throughout the family.

I would never hit my wife. I will never do the emotional games. 'You're no good. You're not worth anything.' I've worked my tail off to do the exact opposite, to make sure that she knows how valuable she is to me. I tell her all the time without her I'd be completely lost. You know the phrase 'the better half'? Yeah, that's true. I think only once have we ever actually, in 10 years, ever yelled at each other? She started crying, I wanted to die. It was horrible. To me it was as bad as hitting her. So when we have, I can't even call them arguments, they're disagreements, voices aren't raised or anything like that, tempers aren't gonna get hot or anything like that. (Ollie, age 40)

I can get really mad, but it never has ever one time occurred to me that it would be a proper and appropriate way to deal with that [anger] would be to strike somebody else, man or woman, child, whatever, you know? Maybe a big part of that is because of what I saw [as a child] and I know what it does. (Joe, age 34)

Identifying and modulating their own anger, and sometimes rage, were challenging issues they faced. Recognizing that one can feel anger, but one can also be in control of its expression was significant to their process.

I kind of have a problem with rage a little bit, and I do get angry. What stops me is just the realization that this is a relationship that I don't want to endanger and I know if I were to strike my wife that relationship would either end or would be in danger. And, it's an important relationship to me and so I'm not willing to take that kind of step. (Eli, age 30)

Participants also reported that their mothers were instrumental in their ability to commit to non-violence as adults. Their mothers' role modeled acceptance of others while they taught lessons of tolerance, compassion, and kindness.

I used to be a lot more like him [father]. After my mom moved out, my sister moved out with her. I stayed with my dad and, and so, when I was living with him I was, in a lot of ways, a mirror of him. Very 'my way or the highway' in thinking, when it comes to dealing with people, you know, arrogant. I'm very tolerant. Like my mom, I think I got that from her. I get along with people a lot better than my dad did. My mom's really nice, so I just took from her in the way I treat other people. She very much tries to live by like the Golden Rule. I'm not a violent person. I couldn't see hurting, hitting someone that I love. I don't think people have the right to hit other people. (Zach, age 23)

I think our attitude towards life, we're [mother and son] probably similar. Upbeat, positive attitude. She likes to have fun. She likes to get out and do things. She's very caring, and I like to say that I'm a very caring individual also. We've always had a close relationship. I'd probably have to say my mother really tried to instill how to treat a woman. No matter what the situation is you don't hit a woman. And, no matter how upset or anything like that there's never a legitimate reason to hit, or touch a woman like that. So I think that really, carried over. (Benji, age 29)

\section{Understand and Accept Childhood Realities}

Exploring the "why" of exposure to domestic violence was another widely used task to recover from childhood powerlessness. Consistent with the Process-Psychodynamic Treatment Model (PPTM) (Saunders, 1996, pg. 395), this process involved seeking explanations and asking themselves, "Why did my father/stepfather do this?" Participants did not seek explanations for the purpose of excusing the violence, but instead did so to reconsider and accept childhood traumas, grieve their losses associated with these traumas, not control others, and gain empathy for their perpetrators in order to eventually make sense of their childhood adversity. Often gaining understanding of past trauma as well as their parents' life experiences allowed them to humanize them and, consequently, have a relationship with them in adulthood.

A lot of it [IPV] is understanding who they [parents] were at that time, what they went through, understanding why they did what they did. It may not make sense to me, but if I can try and understand how they felt and what they were doing then I can comprehend they weren't just monsters. They were just people trying to do what they could, and they were doing the wrong thing, but honestly I don't think they knew any other way. That then takes the anger out of it and actually makes you sadder, but it takes the anger out. It allows you to feel human to them again, or them to feel human to you again. So you don't have the anger and the bitterness and the hatred 
anymore. I can look at some of those times where at one point I'd be furious and hated them and didn't even want anything to do with them, those feelings have changed. Now when I look back on it, it's not with anger. It's with sadness, regret, you know, wish things could have been different but they weren't. (Ollie, age 40)

During childhood, participants often asked themselves, "Why do my parents fight?" They discussed how when they were younger, they knew their fathers/stepfathers were at fault for the abuse, yet some believed they should have intervened even though, ultimately, they were powerless to do so. Understanding and accepting their family history and its dynamics helped to release their childhood sense of responsibility and guilt.

I think it seems to run in my family quite a bit with guilt. I've been looking at that a lot more and talking to family members more and diving into the family tree and stuff like that. I think that guilt, one of the ways I've been dealing with that is recognizing that number one, it wasn't my fault. Number two, I didn't have anything to do with it. And number three, just understanding responsibility and people being responsible for their own actions. As I've gotten older I've learned you can't stop people from doing things and, therefore, because something happened it doesn't mean that it's my fault or that I provoked it. So I've learned I think over the years to realize that it wasn't anything that I did. (Benji, age 29)

My mom made it a point to let us know that it was nothing that we did. I don't know, I just could never trace it back to something that maybe I could have done that would have set him off, you know, like I was bad in some way and, or anything like that. It just seemed to me that they would get into pretty heated arguments themselves, on their own, completely. (Joe, 34)

By giving themselves permission to understand their fathers/stepfathers (including his family history), participants were empowered to have a say in how they interpreted the causes of violence (innate quality and/or social condition) allowing empathy while not condoning or excusing abusive behavior.

As I've grown older and become an adult, I've tried to look at it from his point-of-view, I've learned things that I've found just absolutely fascinating. He was trapped in a marriage with no love. He was trapped in a job with no future. I have absolutely no doubt he felt absolutely trapped in his life and there was no future for him whatsoever. He felt, I'm pretty sure he felt futile, that there was no control over anything. He would be fine as long as he didn't get angry, lose his temper. But he'd come home, and even if he wasn't physical, it would be an emotional situation, for he had to take control, feel like he was in control of something. (Ollie, age 40)

My father was a very ambitious man. He was a lawyer. He went to a New York law firm, a very prominent New York firm and he worked hard, and he was away from the house for extended periods of time, which was customary for lawyers who were just beginning. And I think that added to it. My mother referred to at times he was not loyal to her in his absences, which I think was a stress from her viewpoint, and he on his side suspected her of infidelity at different times, or accused her. He did not make partner in this law firm after so many years. As a child I wasn't aware of the significance of that.... I perceived that the two [parents] were in an ugly dynamic, and I think they both had problems they brought in from their childhood. I think my father just was reacting in stress, and I think they had certain aspects of their life style just were not conducive to a good family relation. (Gavin, age 60)

\section{Choose to Forgive Parents}

Forgiving their fathers/stepfathers (and for some their mothers for not protecting them) for past violence was also a component in participants' ability to garner a sense of empowerment and counteract childhood powerlessness. Participants did not receive an apology or admission of responsibility for the abuse from their fathers/stepfathers, yet they chose to forgive as a means of taking control of their lives. Forgiveness included letting go of anger and resentment toward their parents and accepting their limitations.

He [father] denied hitting my face when I was two and a half and said my mom was a liar. And I said 'Dad, 15 years ago you admitted to it, and you said that you were gonna pay to have my nosed fixed. You don't recall that?' And he said 'No, I don't recall that.' He defended himself on the phone for five minutes at least trying to convince me that he didn't do it. And I finally came to the point and said 'Dad, it doesn't matter if you did it or not. The point I'm trying to make here is that I forgive you, and I don't care how it happened. I'm just telling you why you were ignored for four years.' (Brad, age 37)

I have healed from it and one way I did was through forgiveness and when my stepfather was in prison for trying to have my mom killed, I wrote him a letter in which I said I forgave him 
for everything he'd done to me, everything he'd done to my family. And I never received anything back, and who knows if he even got it. But, just writing that letter, the catharsis of that really helped me get over it and to this day my brothers and my mom have never taken that step. They've never forgiven him. I came to the conclusion that forgiveness is a two-step process, not a three-step process. I mean some people say it's a three-step process and that someone has to ask forgiveness then I would grant forgiveness and they accept forgiveness. And I think it's a two-step process rather in that I give forgiveness and it's accepted. And the only step in that I have to worry about is the first one that I have to offer forgiveness and then whether it's accepted or not is the other person's problem. And, when I came to that realization, things cleared up for me quite a bit. (Eli, age 30)

For two participants, forgiveness of their fathers was influenced by Christian beliefs, particularly how forgiveness should be extended even if it is not earned. Because God or a Higher Power can forgive human sin, including abuse, they believed that they could do the same with their fathers. Choosing to forgive allowed them to reconcile and accept one's childhood adversity and work toward closure.

It wasn't until I realized that in the Christian experience, one of the pivotal features is whenever Jesus came to pay the debt for our sins, and he did that whenever we didn't deserve it. Part of that paying that debt is forgiveness. If God can forgive me for all the things that I've done, and he can forgive my dad for the stuff that he did, then maybe I can too. And it was that process of really wrapping my mind around the issue of forgiveness, as well as having that kind of acceptance that really helped me over the course of years come to the point that I have a little bit of closure. (Ace, age 26)

Four participants discussed the challenges they had toward forgiving their mothers because of neglect during their childhood due to their mothers' substance abuse, mental health problems, or lack of protection from child abuse. Participants spoke of the importance of coming to understand both parents' shortcomings and of the importance of accepting these hard facts.

I really wish that I would have known that many of the problems that my mother has, mentally and socially or whatever, aren't necessarily her fault, because I did blame her a lot, like "What is your problem? Why do you have so much pity for yourself, why wouldn't you want to live for your kids and do everything you can positively for your children?" I saw her as very selfish and resented that a lot because it was like she's always thinking about herself. She's never thinking about us. I saw my mom just like laying there doing nothing, and so, maybe that point of view [understanding mothers' mental health problems] may have changed how I thought of her. (Rick, age 29)

She [mother] asked me when I was 19, "Why do you hate me so much?" and I'd never really thought of that, and both her and I really looked deep and hard and researched into why I had this hatred towards my mom. We're pretty sure now it's because she didn't do anything about the beatings [he received from his father], and sometimes she would even say to my dad, "You need to take care of your son." She would say that a lot and she would let my father discipline me. I can remember, being almost unconscious and seeing stars and just those words going through my mind when I was little, "Take care of your son." And it was just like I never forgot that. And still to this day I have a little bit of hatred towards my mom; but we've all healed and have moved on. I've forgiven her for that. (Brad, age 37)

\section{Navigate Adult Child-Parental Contact}

Navigating adult child-parental contact was an ongoing and important task for participants in their recovery from childhood powerlessness. Intentional decision-making involved weighing the personal benefits and costs of the relationship (or lack thereof), along with the impact on parents, other family members, and self. As the child-parent relationship shifted over time, adult sons' relationships with their fathers/stepfathers became based more upon personal choice than what was true during childhood. Navigating involved a delicate balance between maintaining a sense of self while defining boundaries with their abusive father figures.

I've also sat down and talked with both my mom and my dad. With my dad, pretty in depth, and told him that [IPV] was unacceptable. That really damaged our relationship. I think I have a good relationship with my dad now, but we both understand there are some areas that we don't talk about. That is pretty much from the time I was about 10 and younger, we don't talk about anything that happened then because, we're not going to open that old wound. Beyond that, I think I have a good relationship with him, but we had to sit down and kind of lay those ground rules with me as an adult. (Ace, age 26)

All participants spoke about protecting themselves emotionally and setting boundaries within the adult child-parent relationship. For these participants, relational decision making was not necessarily influenced by the 
actions of their fathers/stepfathers. Participants did not identify instances of reciprocal support, understanding, or empathy from their father figures. In other words, these adult sons were more likely to have set aside or overcome their violence exposure rather than their fathers/stepfathers changing and/or taking accountability for their actions. Behavioral processes for all participants included distancing themselves (emotionally and/or physically) from their fathers/stepfathers.

Getting away from my father, like there was always, every decision I ever made like when he was in control was there was always two levels I had to consider, like I had to consider what's the best decision here, or what do I want to do, and how is he gonna react, and what decision does he want me to make, you know? So getting out of his control where I completely cut off contact so he had no control whatsoever, really helped me a lot...I'm sufficiently out of his control enough to where I can start maybe having a relationship again, which is nice. I still have to make it clear that you're not ever gonna be able to tell me what to do again. (Jack, age 23)

I've been away from them [parents], I probably hadn't seen them for five years or so, but I would see other family and talk to the other family, talk to them by phone once or twice a month. And as things started falling into place, I found myself able to be closer and closer to them again. Unfortunately, it also coincided with his [father] cancer, but as he was nearing the terminal stages I got to spend about three months down there with him, and we did a lot of talking. He did a lot of crying, well, we both did, and things that were often times left unsaid, it was expressed. Sometimes it wasn't expressed outright by words, but again reading between the lines we would understand one another, what we were talking about. And it really helped. (Ollie, age 40)

The majority of participants reported they had a special relationship with their mothers including offering and receiving assistance, support and protection to and from each other.

I was kind of blessed in a way that I had a mother that always still made us feel loved. She was really strict on us, growing up, but she always made it known how much she loved us, and that's myself, my brother, and my sister. And, I always felt like me being the middle child, they say that middle child can feel ignored or whatever else, but I always felt like I was Mom's favorite. And I'm sure my brother would tell you the same thing. Or my sister. (Jim, age 33)

\section{Access Informal and Formal Support Networks}

Participants gave regular testimony on the importance of having supportive and nonviolent family, particularly their mothers, along with friends, and significant others in their lives. An essential strength of the participants was their ability during times of stress and crisis to seek help, particularly accessing formal networks. Nine participants utilized professional therapy/counseling services which became for them the bridge to facing and dealing with the past.

Well, I think when going through counseling, as I was in college and when the major incidents [IPV] kind of happened, I realized that it is beneficial to talk to somebody. I always thought that talking to a total stranger would be the hardest thing to do. In reality I find it much easier than talking to someone that you know cause you don't have to sustain that relationship outside of that. (Dale, age 48)

It [counseling] was extremely helpful... my grandparents and mom sent me to this therapist so I wouldn't grow up to be gay, so what's funny is they didn't have any idea what [the counselor] and I talked about, and he didn't talk about my sexual orientation but maybe one time, and didn't even go there. All we talked about was my dad and the abuse and the healing and that [counselor] made me heal. I probably saw him every week for a year, that's quite a bit, an hour every week. And I'll tell you that it was an integral part of my healing because once I graduated high school I went right on to college and here I am. I have a career now and a life, and I don't think I could have had that, I know I couldn't have had that, no way... And I tell you, that's probably the reason I'm alive today is because of [the counselor] and I'm not kidding... I was a suicide case. (Brad, age 37)

Receiving pastoral counseling or assistance from a faith community was a form of therapeutic support for two participants. Religious leaders provided counsel, solace, and clarity of scriptures and core doctrines. Participants' religious communities offered emotional comfort, a sense of belonging, and security.

If you are a member of a church and a denomination you are intimately connected to people whether you want to be or not and my church in particular. We have communion every week and so the bread and the wine every week, and that is a metaphysical connection between people. I believe that, and so it's at that point I suppose that some of that scar tissue goes away. I may let people in through that, so that's been a major, major [turning] point for me. (Eli, age 30) 


\section{Discussion}

We are becoming more knowledgeable in all areas of childhood trauma, yet minimal research exists regarding males, who during childhood witnessed their mothers' abuse by an intimate partner and were abused themselves, stop the cycle of violence from continuing in their own lives (Chartier, Walker, \& Naimark, 2010; Dube et al., 2001; Moon, 2000). The seeds of their nonviolence were planted in childhood, as they promised themselves when they grew up that abuse would not be a part of their intimate relationships or in their lives in general. Recognition, understanding and acceptance of the past allowed for closure and paved the way to take hold of personal power in the present. They exercised choice around issues of parental forgiveness and contact. They sought therapeutic support (e.g., counseling or spiritual resources) to better understand their childhood experiences, their parents' actions, and ultimately themselves. Participants realized that their childhood powerlessness was a part of their past, but did not have to be a part of their present or future, allowing them to align with an empowered adult self. Ultimately, they came to own their power as a means of ending the cycle of violence rather than using it to dominate others. In doing so, they wrote their own destinies where physical and emotional safety for self and others was paramount.

These adult sons recognized that they had options in creating the identity and life they desired. Important to their non-violent identity formation included childhood promises to their future selves of nonviolence toward their partners and children. These promises were influenced by lessons learned from their father figures' abusive actions and their mothers' reactions of strength, courage, and resilience in response to such adversity. In other words, formulating self-promises of nonviolence were shaped as much, if not more, by their mothers' responses as opposed to their fathers' behaviors. The majority of participants reported how their mothers served as role models of nonjudgment and gentleness toward others while providing love and support toward them. Research on mediating environmental protective factors for child witnesses include a strong and secure attachment to the non-violent parent (usually the mother) or other significant caregiver (Benavidas, 2015; Gonzales, Chronister, Linville, \& Knoble, 2012; Jenny, Alaggia, \& Niepage, 2016). In addition to protection and security, this study's findings highlight how positive mother-son relationships also serve as models of appropriate social behavior that influence a child's lifelong commitment to non-violence, particularly toward women and children. Even those participants whose mothers were not emotionally available to them during childhood due to mental health or substance abuse problems, reported how they never felt blame for their parents' relationship problems and attributed the cause of violence to their fathers.

Gaining knowledge of family dynamics and history allowed participants to accept their parents and the reasons for their actions. These adult sons could see their parents' realities more clearly and accept them for being flawed individuals. Viewing their parents from a lens of empathy also gave them a sense of control over their situation and a better understanding about why the abuse occurred. Learning to become empathetic with others is often the final objective in psychodynamic work completed with not only men who batter, but adults who have experienced and witnessed domestic violence as children. Accepting past abuse helps men grieve their loss and eventually relinquish control over their parents (Browne, Saunders, \& Staecker, 1997; Wexler, 1999).

For these adult sons, forgiveness implied letting go of anger and bitterness toward their father figures and accepting them for who they are, regardless if past hurts had been recognized or addressed by them. The model of forgiveness described by Gordon \& Baucom (1998) presents forgiveness as a three-stage process by which the forgiver develops a definition and understanding of the betrayal, releases negative feelings toward the betrayer, and finds a sense of power in the relationship. Although this model was originally developed for marital betrayal among intimate partners, it is applicable to participants in our study, as they experienced a similar process in adulthood regarding forgiveness of their fathers (and in some cases their mothers). Such findings demonstrate the importance of assessing how individuals forgive, what environmental factors can influence that forgiveness, and how relationships with parents might influence forgiveness and healing for adult children from partner-abusive households since these processes seem to be linked to lessening some of the negative effects of having witnessed domestic violence as a child (Suzuki, Geffner, \& Bucky, 2008).

Navigating adult child-parental relations was a key finding for adult sons in this study (Anderson \& Danis, 2006, Anderson, Danis, \& Havig, 2011). Setting limits, particularly with exposure to abuse and dysfunction, along with distancing oneself emotionally and/or physically from their parents, was vital for these adult sons in stopping the cycle of violence. Participants' relations with their parents involved an ebb and flow of maintaining, minimizing, and/or stopping contact altogether. To understand such choices and its impact on parental contact, this study's results provide useful information for adult sons, who are trying to steer role obligation, responsibility, and conflict (including power differentials) under the lasting impact of childhood exposure to domestic violence.

Each participant noted the influence of therapeutic and/or religious support on helping them move beyond the difficulties of the past and seize control of the present. Adult sons turned to spiritual support for solace, security, and a sense of belonging. A Higher Power served as a guide and influence for offering parental forgiveness, but was not relied upon to foster a sense of purpose and value in life. Adult sons in this study, therefore, were less likely to report 
posttraumatic growth as a result of their suffering; finding meaning and renewal in the aftermath of trauma. (Helgeson, Reynolds, \& Tomich, 2006).

\section{Limitations}

This qualitative study was based on a small sample size with limited ethnic and racial diversity and included the possibility of selection bias with regards to decision to participate in the study. Participants in this sample were also well educated and there may be different pathways to ending the cycle of violence based on level of education. We accepted participants' perceptions of their experiences during the in-depth interviews; in doing so, we did not seek additional input from others in participants' social ecologies regarding their assertions of non-violence. Findings from the qualitative data analysis of the larger study of adult children indicated thematic differences between those males who reported partner abuse $(n=5)$ and those who did not $(n=13)$, particularly in how they came to own their power as either a means of ending the cycle of violence or for using it to dominate others.

\section{Implications}

Participants altered their childhood patterns of thinking, behaving, and feeling influenced by schemas of powerlessness to ones of control and choice in adulthood. Our findings align with Gutierrez's (1990) empowerment conceptualization as "a process of increasing personal, interpersonal, or political power so that an individual can take action to improve their life situations" (pg.149). Five strategies were used to garner empowerment or "gain mastery over their affairs" in adulthood (Rappaport, 1987, pg. 122): commitment to nonviolence, understand and accept childhood realities, forgiveness of parents, navigation of parental contact, and accessing support. In doing so, participants were able to attain informed life choices, develop healthy relationships, and increase a sense of control and self-determination within their own lives.

The empowerment perspective within the context of intimate partner violence (IPV) arose from the feminist movements of the 1960s, which framed domestic violence within a social, cultural and historical framework of power inequality between the sexes (Busch \& Valentine, 2000). The "Power and Control/Equality Wheels" are popular educational tools of relationship dynamics used in domestic violence shelters and coalitions across the United States. Building upon prior work exploring and examining women's empowerment in the context of IPV (Busch \& Valentine, 2000; Davis \& Srinivasan, 1995; Gutierrez, et al., 1998; Kasturirangan, 2008), our findings underscore how empowerment is essential, as well, for nonviolent adult sons of abused women in stopping the cycle of violence. We developed the "Empowerment Wheel for Sons of Abused Women" (see Figure 1) as an educational and therapeutic tool for helping professionals to use with male witnesses to prevent the intergenerational transmission of violence. 


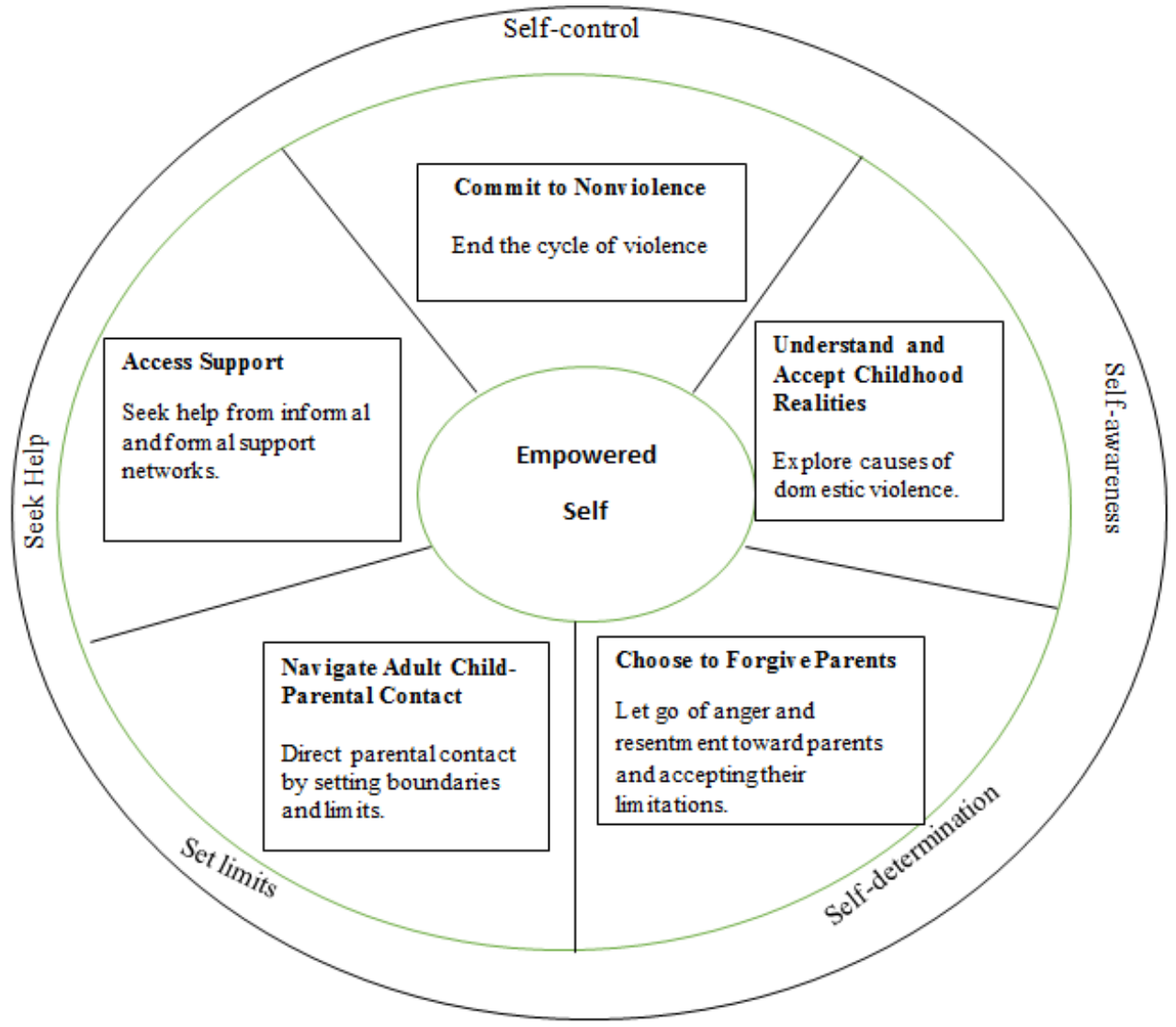

Figure 1. Empowerment Wheel for Adult Sons of Abused Women

1. Commit to nonviolence. For boys, to help them explore promises to their future selves in regard to how they would like to be different, as partners and parents, from their own abusive fathers. Equally important is identifying positive qualities of nonviolence in their mothers that may serve as guideposts for considerate and caring social behavior toward others in general, and females in particular. For adult males, to help them align with their childhood commitment of nonviolence, along with personal understandings regarding the toll violence has on the family. For male children and adults, learning nonviolent ways to communicate their anger is also essential.

2. Understand/accept childhood. For boys, assisting them to understand the power their fathers have in causing the violence; thereby relinquishing the guilt they have as children regarding their own abilities to influence the environment. For adult males, helping them understand the context of their fathers' actions, including familial stressors, resources, and history, as a means of understanding, but not condoning the causes of violence.

3. Choose to forgive parents. For boys, acknowledging their parents' caregiving limitations, while not accepting the violence or their "fate" of continuing the cycle (e.g., boys growing up to be abusers). For adult males, recognizing that although their fathers may not extend forgiveness, they can still release negative feelings; thereby, finding a sense of power in the relationship and within themselves.

4. Navigate child-parental contact. For boys, they are limited in what they can do as children to direct parental contact; thus, safety planning with the child and non-abusive parent is necessary including accessing informal (e.g., grandparents, neighbors) and formal (e.g. police, domestic violence programs, school personnel) protective mechanisms. For adult males, learning to limit exposure to parental violence and dysfunction (e.g., alcohol abuse) provides a means of protecting themselves emotionally and physically, while controlling what influences (e.g., patriarchal values) are not allowed into their environment.

5. Access support. For boys, providing opportunities for therapeutic support within the school system and/or other counseling options for them to process their cognitive, emotional, and behavioral reactions to witnessing (and for some directly experiencing) family violence. For adult males, to continue to find support either therapeutically or spiritually as a means of taking stock of their lives, making decisions of how they want to act as partners and fathers, along with not letting the past dominate the present. Helping them to recognize the importance of controlling their own nonviolent destinies. 


\section{Conclusions}

There is much about domestic violence that is paradoxical and thus difficult to make sense of for children (e.g., "Why does my father hurt someone he loves?"). As these sons matured into adulthood, they continued to look for ways to better understand and heal from their childhood exposure experiences. Their desire to act on that knowledge was associated with five empowerment strategies germane to transforming their childhood powerlessness into adult lives of choice, pride, and potential.

\section{REFERENCES}

Anderson, K. M., \& Bang, E. (2012). Assessing PTSD and resilience for females who during childhood were exposed to domestic violence. Child \& Family Social Work, 17, 55-65.

Anderson, K. M., \& Danis, F. S. (2006). Adult daughters of battered women: Resistance and resilience in the face of danger. Affilia, 21(4), 419-432

Anderson, K. M., Danis, F. S., \& Havig, K. (2011). Adult daughters of battered women: Recovery and posttraumatic growth following childhood adversity. Families in Society, 92(2), 154-160.

Band-Winterstein, T. The impact of lifelong exposure to IPV on adult children and their aging parents. Journal of Family Issues, 35(4), 439-461.

Benavides, L. E. (2015). Protective factors in children and adolescents exposed to intimate partner violence: An empirical research review. Child \& Adolescent Social Work Journal, 32, 93-107.

Boxer, P., \& Sloan-Power, E. (2013). Coping with violence: A comprehensive framework and implications for understanding resilience. Trauma, Violence, and Abuse, 14(3), 209-221.

Browne, K., Saunders, D., \& Staecker, K. (1997). Process-psychodynamic groups for men who batter: A brief treatment model. Families in Society: The Journal of Contemporary Social Services, 78(3), 265-271.

Chartier, M., Walker, J. R., \& Naimark, B. (2010). Seperate and cumulative effects of adverse childhood experiences in predicting adult health and health care utilization.' Child Abuse and Neglect, $34,454-464$

Clements, C. M., Oxtoby, C., \& Ogle, R. L. (2008). Methodological issues in assessing psychological adjustment in child witnesses of intimate partner violence. Trauma, Violence, and Abuse, 9(2), $114-127$

Connor, K. M., \& Davidson, J. R. T. (2003) Development of a new resilience scale: The Connor-Davidson Resilience Scale (CD-RISC). Depression and Anxiety, 18(2), 76-82.

Davis, L. V., \& Srinivasan, M. (1995). Listening to the voices of battered women: What helps them escape the violence? Affilia, 10, 49-69

Dedoose. Discover Dedoose qualitative and mixed methods research. Retrieved June 1, 2013, from http://app.dedoose.com/LearnMore/
Dick, G. (2005). Witnessing marital violence as children: Men's perceptions of their fathers. Journal of Social Service Research, $32(2), 1-24$.

Dube, S. R., Anda, R. F., Felitti, V. J., Edwards, V. J., Williamson, D. F.\& Giles, W. H. (2001). Exposure to abuse, neglect, and household dysfunction among adults who witnessed intimate partner violence as children: Implications for health and social services. Violence and Victims, 17(1), 3-17.

Edleson, J. L., Ellerton, A. L., Seagren, E. A., Kirchberg, S. L., Schmidt, S. O., \& Ambrose, A. T. (2007). Assessing child exposure to adult domestic violence, Children and Youth Services Review, 29(7), 961-971.

Enoch, G., \& Buchbinder, E. The interactive construction of narrative styles in sensitive interviews: The case of domestic violence research. Qualitative Inquiry 11 (2005): 588-617.

Evans, S., Davies, C., \& DiLillio, D. (2008). Exposure to domestic violence: A meta-analysis of child and adolescent outcomes. Aggression \& Violent Behavior, 13(2), 131-140.

Fagan, A. A., \& Wright, E. M. (2011). Gender differences in the effects of exposure to intimate partner violence on adolescent violence and drug use. Child Abuse \& Neglect, 35(7), 543-550.

Franklin, C. A., Menaker, T. A., \& Kercher, G. A. (2012). Risk and resilience factors that mediate the effect of family-of-origin violence on adult intimate partner victimization and perpetration. Victims and Offenders, 7, 121-142.

Garofaolo, E. W. (2010) The contributions of Ellen Pence to batterer programming. Violence against Women, 16(9), 992-1006.

Gelles, R. J., \& Straus, M. A. (1979). Determinants of violence in the family: Toward a theoretical integration. The Family and Problems, 549-581.

Glaser, B. G. (2001) The grounded theory perspective: Conceptualization contrasted with description. Mill Valley, CA: Sociology Press.

Gonzales, G., Chronister, K. M., Linville, D., \& Knoble, N. B. (2012). Experiencing parental violence: A qualitative examination of adult men's resilience. Psychology of Violence, 2(1), 90-103.

Gordon, K. C., \& Baucom, D. H. (1998). Understanding betrayals in marriage: A synthesized model of forgiveness. Family Process, $37(4), 425-429$.

Gutierrez, L. M. (1990). Working with women of color: An empowerment perspective. Social Work, 35, 149-153.

Helgeson, V. S., Reynolds, K. A., \& Tomich, P. L. (2006). A meta-analytic review of benefit finding and growth. Journal of Consulting Clinical Psychology, 74(5), 707-816.

Henning, K., Leitenberg, H., Coffey, P., Turner, T., \& Benett, R. T. (1996). Long-term psychological and social impact of witnessing physical conflict between parents, Journal of Interpersonal Violence, 11(1), 35-51.

Herrera, V. M., \& McCloskey, L. A. (2001). Gender differences in the risk for delinquency among youth exposed to family violence. Child Abuse \& Neglect, 25, 1037-1051.

Hines, D. A., \& Saudino, K. J. (2002). Intergenerational transmission of intimate partner violence: A behavioral genetic perspective. Trauma, Violence, \& Abuse, 3(3), 210-225. 
Holt, J., \& Gillespie, W. (2008). Intergenerational transmission of violence, threatened egoism, and reciprocity: A test of multiple pychosocial factors affecting intimate partner violence. American Journal of Criminal Justice, 33(2), 252-266.

Humphreys, J. C. (2001). Turnings and adaptations in resilient daughters of battered women. Journal of Nursing Scholarship, $33(3), 245-251$

Ireland, T. O., \& Smith, C. (2009). Living in partner-violent families: Developmental links to antisocial behavior and relationship violence. Journal of Youth and Adolescence, 38, 323-339.

Jenny, A., Alaggia, R., \& Niepage, M. (2016). “The lie is it's not going to get better": Narratives of resilience from childhood exposure to intimate partner violence. International Journal of Child and Adolescent Resilience, 4(1), 64-76.

Jouriles, E. N., McDonald, R., Smith, A. M., Heyman, R. E., \& Garrido, E. (2008). Child abuse in the context of domestic violence: Prevalence, explanations, and practice implications. Violence and Victims, 23(2), 221-235.

Kasturirangan, A. (2008) Empowerment and programs designed to address domestic violence. Violence Against Women, 14(12), $1465-1475$.

Kitzmann, K. M., Gaylord, N. K., Holt, A. R., \& Kenny, E. D. (2003). Child witnesses to domestic violence: a meta-analytic review. Journal of Consulting and Clinical Psychology, 71(2), 339.

Kwong, M. J., Bartholomew, K., Henderson, A. J. Z., \& Trinke, S. J. (2003). The intergenerational transmission of relationship violence. Journal of Family Psychology, 17, 288-301.

Krieder, R.M. \& Ellis, R. U.S. Census Bureau. (2011). Number, Timing, and Duration of Marriages and Divorces: 2009. Current Population Reports, P70-125). Washington, DC: U.S. Government Printing Office.

Krippendorff, K. (1980) Content analysis: An introduction to its methodology. Thousand Oaks, CA: SAGE.

Maker, A. H., Kemmelmeier, M., \& Peterson, C. (1998) Long-term psychological consequences in women of witnessing parental physical conflict and experiencing abuse in childhood, Journal of Interpersonal Violence, 13(5), 574-589

Miller, S. (2010) Discussing the Duluth Curriculum: Creating a process of change for men who batter. Violence against Women, 16(9) 1007-1021.

Moon, M. (2000) Retrospective reports of interparental abuse by adult children from intact families, Journal of Interpersonal Violence, 15(12), 1323-1331.

Oktay, J. S. (2012) Grounded theory. New York: Oxford University Press.

Mohr, W. K., \& Tulman, L. J. (2000). Children exposed to violence: Measurement considerations within an ecological framework. Advances in Nursing Science, 23(1), 59-68.

Morgolin, G., \& Gordis, E. B. (2004). Children's violence exposure in the family and community. Current Directions in Psychological Science, $13,152-155$.
Murrell, A. R., Merwin, R. M., Christoff, K. A., \& Henning, K. R. (2005). When parents model violence: The relationship between witnessing weapon use as a child and later use as an adult. Behavior and Social Issues, 14, 128-133.

Pence, E., \& Paymar, M. (2003). Creating a process of change for men who batter: The Duluth curriculum. Duluth: Minnesota Program Development. Available from http://www.Duluth-Model.org

Ponce, A. N., Williams, M. K., \& Allen, G. J. (2004). Experience of maltreatment as a child and acceptance of violence in adult intimate relationships: Mediating effects of distortions in cognitive schemas. Violence and Victims, 19(1), 97-108.

Reinharz, S., \& Davidman, L. Feminist methods in social research. New York: Oxford University Press, 1992.

Rappaport, J. (1987). Terms of empowerment/exemplars of prevention: Toward a theory for community psychology. American Journal of Community Psychology, 15(2), 121-149.

Renner, L. M., \& Slack, K. S. (2006). Intimate partner violence and child maltreatment: Understanding intra- and intergenerational connections. Child Abuse and Neglect, 30, 599-617.

Russell, D., Springer, K.W., \& Greenfield, E. A., (2010). Witnessing domestic abuse in childhood as an independent risk factor for depressive symptoms in adulthood. Child Abuse \& Neglect, 34, 448-453.

Saunders, D.G. (1996). Feminist-cognitive behavioral and process-psychodynamic treatments for men who batter: interaction of abuser traits and treatment models. Violence and Victims, 11(4), 393-414.

Song, L., \& Shih, C. (2010). Recovery from partner abuse: The application of the strengths perspective. International Journal of Social Welfare, 19, 23-32.

Stith, S. M., Rosen, K. H., McCollum, E. E., \& Thomsen, C. J. (2004). Treating intimate partner violence within intact couple relationships: Outcomes of multi-couple versus individual couple therapy. Journal of Marital and Family Therapy, 30(3), 305-318.

Stith, S. M., Rosen, K. H., Middleton, K. A., Busch, A. L., Lundeberg, K., \& Carlton, R. P. (2000). The intergenerational transmission of spouse abuse: A meta-analysis. Journal of Marriage and Family, 62, 640-654.

Suzuki, S. L., Geffner, R., \& Bucky, S. F. (2008). The experiences of adults exposed to intimate partner violence as children: An exploratory qualitative study of resilience and protective factors, Journal of Emotional Abuse, 8(1/2), 103-121.

Thompson, E. H., \& Trice-Black, S. (2012). School-based group interventions for children exposed to domestic violence. Journal of family violence, 27(3), 233-241.

Weathers, F. W., Litz, B. T., Huska, J. A., \& Keane, T. M. (1994) The PTSD checklist-civilian version (PCL-C). Boston, MO: Thompson, E. H., \& Trice-Black, S. (2012). School-based group interventions for children exposed to domestic violence. Journal of family violence, 27(3), 233-241.

National Center for PTSD.

Wolfe, D. A., Crooks, C. V., Lee, V., McIntyre-Smith, A., Jaffe, P. G. (2003). The effects of children exposure to domestic violence: a meta-analysis and critique. Clinical Child and Family Psychology Review, 6(3), 171-187. 
Vol.5. No.3 August, 2017, pp. 105-117

Wexler, D. B. (1999). The broken mirror: A self-psychological treatment perspective for relationship violence. The Journal of Psychotherapy Practice and Research, 8(2), 1-22. 